\title{
CAPITALISMO, CUESTIÓN AGRARIA Y LUCHAS POLÍTICAS EN BRASIL (1964-2014)
}

\author{
João Márcio Mendes Pereira* \\ Paulo Alentejano**
}

ResUmen: Este artículo analiza las luchas sociales y políticas que configuraron las relaciones de poder en el campo brasileño en los últimos 50 años, entre 1964 y 2014, cubriendo tanto la dictadura como el régimen democrático. Se enfatizan los procesos organizacionales de los principales actores, las dinámicas de la correlación de fuerzas en la sociedad civil y las acciones del Estado brasileño para preservar o transformar la estructura agraria y la agricultura. El texto empieza viendo las luchas sociales desde el inicio de los años sesenta hasta el golpe de 1964 y la política agraria de la dictadura, enfatizando el proceso de modernización de la agricultura y sus contradicciones principales. Después, se enfoca en disputas sobre la reforma agraria durante el periodo de transición democrática. Seguidamente, se estudiarán las administraciones de Fernando Collor e Itamar Franco, un periodo que marcó un momento de transición al neoliberalismo. Luego el análisis se concentra en las luchas que tuvieron lugar durante los dos mandatos de Fernando Henrique Cardoso y Lula da Silva, llegando finalmente a la administración de Dilma Rousseff.

PALABRAS ClAVE: reforma agraria, movimientos sociales, dictadura, democracia, Brasil.

\footnotetext{
* Profesor de la Universidad Federal Rural de Río de Janeiro, Brasil.

** Profesor adjunto en el Departamento de Geografía de la Universidad del Estado de Río de Janeiro, Brasil.

Traducción del inglés de Igor Ampuero.
} 
ABSTRACT: This article analyzes the social and political struggles which shaped the relations of power in the Brazilian countryside over the last fifty years. Organizational processes of the key actors, the dynamics of power relations within civil society, and the actions of the Brazilian state aimed at preserving or transforming the agrarian structure and agriculture are emphasized. The text begins by looking at social struggles from the beginning of the 1960s until the 1964 coup and the agrarian policy of the dictatorship, emphasizing the process of the modernization of agriculture and its principal contradictions. Next, it focuses on disputes over agrarian reform during the democratic transition period. Following this, the Collor and Itamar Franco administrations are examined, a period which marked the transition to neo-liberalism. Then the analysis will concentrate on the struggles which occurred during the two mandates of Fernando Henrique Cardoso and Lula da Silva, and finishing with the Dilma Rousseff administration.

KEY WORDS: agrarian reform, social movements, dictatorship, democracy, Brazil. 


\section{DEL CRITICISMO DEL LATIFUNDIO A LAS REFORMAS ESTRUCTURALES (PRE-1964)}

$\mathrm{E}$ ntre 1945 y 1964, los campesinos ganaron visibilidad en el espacio público y aparecieron políticamente en el escenario nacional en forma de varias organizaciones. En las luchas por la tierra, mejores condiciones de trabajo y derechos, resistieron intentos de ser expulsados de propiedades grandes, realizaron marchas y protestas en las ciudades, organizaron sus propios congresos, acamparon fuera de ranchos grandes y empezaron a ocupar algunos de ellos para forzar al gobierno federal a expropiarlos. En esta trayectoria estaba involucrada la competencia entre agentes que se disputaban la representación de estos grupos sociales, como la Iglesia católica y los partidos políticos, en particular el Partido Comunista Brasileño (Partido Comunista Brasileiro - $\mathrm{PCB}-$ ). Durante dos décadas estas luchas se tradujeron a un lenguaje común entre varios actores sociales y convergieron en la defensa de la ampliación de la legislación laboral al campo y la reforma agraria general en el campo (Camargo, 1981; Ianni, 1984; Medeiros, 1989; Welch, 1999).

En efecto, la crítica del latifundio - grandes plantaciones o granjasestaba en el corazón de las discusiones para superar los problemas estructurales de la nación al inicio de la década de los sesenta. Muchas corrientes de pensamiento consideraron la alta concentración de posesión de tierras como el principal responsable del escenario de baja productividad, atraso tecnológico y relaciones laborales arcaicas que caracterizaron a la agricultura, también se la consideró como un obstáculo para la industrialización. Más que esto: desde el punto de vista político, el latifundio fue visto como la base de un sistema de dominación que despojó a los campesinos de derechos y condiciones de vida digna. ${ }^{1}$

Esto no fue una cuestión restringida a las fronteras nacionales. Después del inicio de la guerra fría, Washington usó la promoción del

${ }^{1}$ La legislación laboral creada en los años treinta durante la primera administración de Getúlio Vargas (1930-1945) no se extendía al campo. Mientras Brasil se industrializaba, el latifundio permanecía como territorio de gobierno personal fuera del universo legal. 
desarrollo en los países del tercer mundo como una política para contener al comunismo. En 1949, como parte de esta estrategia, la administración Truman lanzó el programa de cuatro puntos, que permitió el suministro de ayuda técnica y financiera para países considerados subdesarrollados. La modernización de estructuras agrarias consideradas atrasadas e ineficientes se manifestó como una directiva, aunque en la práctica las acciones reformistas fueron combatidas por el gobierno de Estados Unidos y sus aliados. Con la victoria de la Revolución cubana, este criticismo se añadió a la preocupación de que la agitación social podría comprometer el orden político de la región. En 1961, a cambio de asistencia económica, la Alianza por el Progreso propuso que los gobiernos lleven a cabo reformas agrarias moderadas. Se logró muy poco con esta iniciativa, pero la posición de Washington ayudó a apoyar la discusión sobre la necesidad de reformar las estructuras agrarias nacionales para lograr eficiencia económica e igualdad social.

Aun a nivel internacional, en ese periodo un referente con fuerte influencia sobre el pensamiento económico latinoamericano fue la Comisión Económica para América Latina y el Caribe (CEPAL). La superación del subdesarrollo tuvo lugar a través de la industrialización por sustitución de importaciones, lo que dependió de la remoción de «obstáculos», como una estructura agraria dual basada en la división latifundio-minifundio. Por tanto, la reforma agraria fue vista como la responsable de distribuir la posesión de tierras de una forma más balanceada.

En otras palabras, durante ese periodo hubo una confluencia de distintos conceptos de desarrollo y perspectivas políticas impulsadas por factores externos e internos, que convergieron en la crítica de la concentración privada de tierra y la defensa de la reforma agraria por varios sectores de la sociedad brasileña como una medida de justicia social y progreso económico, y parte de las «reformas estructurales» que se suponía resolverían los importantes problemas nacionales.

En 1962, la administración João Goulart creó la Superintendencia de Reforma Agraria (Supra) y en el año siguiente el Congreso brasileño aprobó el estatuto del trabajador rural (Estatuto do Trabalhador Rural 
-ETR-), extendiendo la legislación laboral al campo, 20 años después de las ciudades. También en 1962 el sindicalismo rural fue regulado, llevando a la rápida expansión de sindicatos de trabajadores rurales en todos los estados brasileños. ${ }^{2}$ Este proceso culminó a finales de 1963 con la creación de la Confederación Nacional de Trabajadores Agrícolas (Confederação Nacional de Trabalhador na Agricultura - Contag-), que centralizó la representación sindical de los «trabajadores rurales», una categoría legal impuesta por la legislación que cubría los diferentes tipos de campesinos parceiros, meeiros, arrendatários (los tres son tipos de aparceros), posseiros (ocupantes ilegales), pequeños granjeros, trabajadores empleados permanente y temporalmente, entre otros. En el mismo periodo, se formó el Movimiento de Agricultores sin Tierra (Movimiento dos Agricultores sem Terra -Master-) en Río Grande do Sul, y las Ligas Campesinas (Ligas Camponesas) en el noreste.

Las organizaciones de empleadores, como la Sociedad Nacional de Agricultura (Sociedade Nacional de Agricultura - SNA-) y la Sociedad Rural Brasileña (Sociedade Rural Brasileira - SRB-) abogaron por la defensa del «derecho sagrado a la propiedad». ${ }^{3} \mathrm{Su}$ principal argumento contra la crítica del latifundio fue que el sector agrícola había sido abandonado por el Estado y era penalizado por la política económica favorable a la industrialización (Medeiros, 1983; Tapia, 1986).

El 13 de marzo de 1964, el presidente firmó un decreto que permitía la expropiación para la reforma agraria de tierras ubicadas a 10 kilómetros de caminos, vías férreas y presas construidas por el gobierno

2 Ya que la ley sólo autorizaba un sindicato de trabajadores por municipalidad, había una carrera entre varias fuerzas políticas (principalmente el рсв у sectores vinculados a la Iglesia) buscando reconocimiento legal para «sus» sindicatos (Medeiros, 1989: 78).

3 Fundado en Río de Janeiro en 1896, sna tenía una base social nacional y representaba los intereses de grandes terratenientes ligados a las cadenas productivas menos dinámicas en el país, que se disputaban el liderazgo entre la clase dominante con la burguesía del café de São Paulo. Entre 1930 y 1964, SNA se convirtió en una fuerza hegemónica en el aparato estatal. A su vez, la SRB fue fundada en la ciudad de São Paulo en 1919, tenía una base social regional y representaba a la burguesía de café de São Paulo, al igual que intereses comerciales de los sectores exportadores, procesadores de productos agrícolas e industriales (véase Mendoça, 2011). 
federal. Dos días después, en medio de intensas movilizaciones populares y sindicales, Goulart envió un mensaje al Congreso proponiendo cambios legales dirigidos a la reforma agraria. Fue una respuesta moderada a las movilizaciones campesinas que demandaban reforma agraria «por ley por garrote» (Bruno, 1997: 97; Mendonça, 2011: 40). Unos días después el golpe cívico-militar tuvo lugar, ${ }^{4}$ producto de una asociación política que tenía el apoyo ostensivo de organizaciones de empleadores rurales.

\section{DICTADURA Y MODERNIZACIÓN DE LA AGRICULTURA} (1964-1985)

El golpe interrumpió violentamente un ciclo de luchas populares que demandaban la implementación, consolidación y expansión de derechos laborales y sociales en el campo y las ciudades, al mismo tiempo que confirmaba la hegemonía del capital monopólico internacional (Mendonça, 2011). Sin embargo, la represión no fue suficiente para eliminar la crítica al latifundio y las expectativas populares de reforma agraria. Aunque anuló inmediatamente el decreto de expropiación de tierras, el gobierno hizo redactar el Estatuto de Tierra (Estatuto da Terra - ET-), que fue aprobado por el Congreso en noviembre de 1964. Además, el Congreso también aprobó un cambio en el artículo de la constitución de 1946 que requería un pago en efectivo adelantado como indemnización en el caso de expropiación, permitiendo hacer el pago en bonos gubernamentales canjeables a largo plazo. Esta medida había sido una de las principales demandas de los campesinos en años anteriores (Gomes da Silva, 1987; Medeiros, 1989).

Después de catorce diferentes versiones, el Ет fue definido oficialmente más como una ley de desarrollo rural que como reforma agraria. Lleno de una ideología de planeamiento y racionalidad técnica, contenía

\footnotetext{
${ }^{4}$ Ese término fue acuñado por René Dreifuss (1989) y designaba un golpe de clase, con un perfil comercial militar apoyado por Washington.
} 
dos partes diferentes, una dirigida al desarrollo y la otra a la reforma (Graziano da Silva, 1985; Gomes da Silva, 1996; Martins, 1981, 1984; Bruno, 1997). Las propiedades rurales se tipificaron como minifundios (con área menor que un módulo rural, ${ }^{5}$ por lo tanto insuficiente para mantener una familia), latifundios por explotación (entre uno y 600 módulos, con un índice de explotación económica menor al del promedio regional), latifundios por tamaño (superior a 600 módulos, sin tomar en cuenta su actividad económica), y compañías rurales (entre uno y 600 módulos, caracterizados por el uso adecuado del suelo, explotación racional, conformidad con la legislación laboral y preservación de recursos naturales). El objetivo de la reforma fue «asegurar una mejor distribución de la tierra [...], para cumplir con los principios de justicia social y el incremento de la productividad». El camino a esto sería la extinción gradual de los minifundios y latifundios. El ideal era la «compañía rural», que estaba exenta de expropiación y de la cual surgieron todos los otros conceptos. El latifundio iba a ser convertido en compañías a través de tributación progresiva, soporte técnico y asistencia financiera, o expropiación (en el caso de conflicto social). ${ }^{6}$

Este marco proporcionó una infraestructura conceptual y legal que llegó a servir como los cimientos no sólo para la acción (federal y a veces estatal) gubernamental y judicial, sino también para las luchas de los campesinos,

\footnotetext{
${ }^{5}$ Modelo rural es una unidad de medición, expresada en hectáreas, que busca reflejar la interdependencia entre las dimensiones, la situación geográfica de la pobreza rural y las condiciones de su uso económico. Por tanto, un módulo se presenta en tamaño variable que debe tener una unidad para permitir subsistir a una familia.

${ }^{6}$ En 1996, la Constitución Federal creó los Bonos de Deuda Agraria (Títulos da Dívida Agrária - TDAs-) como valores gubernamentales para la deuda interna a través de los cuales el Estado indemnizó el valor de la tierra expropiada, mientras que las mejoras tenían que ser pagadas en dinero. Después de un periodo de gracia de dos años, éstos podrían ser reclamados anualmente por los portadores en porcentajes variables, dentro un periodo máximo de 20 años. De acuerdo con el Decreto 554 de 1969, el valor de la compensación se vinculó a los valores declarados por los propietarios para el pago del Impuesto de Tierras Rural (Imposto Territorial Rural - ITR-). Sin embargo, este decreto no fue seguido por las cortes estatales, que juzgaron que el valor de la compensación debería estar de acuerdo con los precios del mercado. En 1979 una corte federal encontró el Decreto 554/69 inconstitucional, restaurando el criterio de valor de mercado para el pago de indemnización por tierra expropiada (véase Gomes da Silva, 1987 y 1989; Graziano da Silva, 1982).
} 
configurando no sólo una manera de categorizar y clasificar el ambiente rural, sino también un campo de disputas políticas y legales. La noción genérica actual de «trabajador rural» impuesta por la legislación terminó deshaciéndose de otras atribuciones para el reconocimiento de demandas por el Estado, convirtiéndose en crucial para las acciones de la Contag durante los años setenta y ochenta (Palmeira, 1985; Medeiros, 1989).

Junto a la aprobación del ET, se eliminó a Supra y se crearon dos nuevas agencias: el Instituto Brasileño de Reforma Agraria (Instituto Brasileiro de Reforma Agraria - IBRA-), subordinado a la Presidencia de la República, y el Instituto Nacional de Desarrollo Agrario (Instituto Nacional de Desenvolvimento o Agrário - INDA -), vinculado al Ministerio de Agricultura. La duplicidad de agencias institucionalizó la división política entre «reforma»y «desarrollo».

Aunque el ET permitió que se llevara a cabo la reforma agraria con una inclinación modernizadora y productivista, lo que fue apoyado en parte por el gobierno en sus primeros meses, la política de la dictadura terminó siguiendo el camino de la modernización conservadora de la agricultura, prescindiendo de la reforma agraria (véase Graziano da Silva, 1982; Ianni, 1979 y 1979a; Delgado, 1985; Gonçalves, 1997; Palmeira y Leite, 1997). Este camino llevó a un cambio significativo en la base técnica y productiva del sector agrícola a través de la adopción de la mecanización intensiva y el uso de agrotoxinas, fertilizantes químicos y semillas seleccionadas, favoreciendo la concentración de la producción en grandes propiedades.

Se usaron varios instrumentos para hacer factible esta modernización, notablemente los créditos subvencionados, a través del Sistema Nacional de Crédito Rural, creado en 1965, concedió grandes sumas a los negocios agrícolas en el centro y sur del país, privilegiando productos destinados a la exportación o vinculados a programas energéticos, como el Programa Nacional de Alcohol (Proálcol), creado poco después de la crisis de petróleo de 1973. Además de crédito, el Estado también financió la investigación agrícola, asistencia técnica y educación técnica y de tercer nivel, necesaria para el entrenamiento de profesionales especializados. 
Otro instrumento usado ampliamente fue el de los incentivos fiscales dirigidos a subsidiar la compra de grandes pedazos de tierra e implementar proyectos agrícolas grandes para los empresarios urbanos, en especial en las regiones del norte y el noreste. Estas operaciones fueron estimuladas a través de una exención fiscal del impuesto sobre productos industrializados y el impuesto sobre ingresos, al igual que subsidios para agencias de desarrollo regionales. Además, hubo una transferencia masiva de tierras públicas a agentes privados a través de subastas y licitaciones públicas que beneficiaron a grandes terratenientes y grupos industriales y financieros.

El gobierno también usó la política de precio mínimo garantizado, favoreciendo las unidades productoras (más grandes), como las cooperativas y agroindustrias, lo que contribuyó a consolidar cadenas de producción y el sector de la agroindustria.

Después de tomar en cuenta todo lo anterior, no es difícil concluir que, más que el simple mediador de los intereses, el Estado fue protagonista de este proceso. A través de agencias y agentes estatales, ${ }^{7}$ las tierras rurales se convirtieron en un negocio altamente rentable durante la dictadura.

La ruta conservadora a la modernización de la agricultura brasileña habría sido impensable sin el extremadamente favorable escenario internacional, debido tanto a la alta demanda por exportaciones agrícolas como a la abundancia de créditos baratos. Su trayectoria mostró que la reforma agraria no era una condición indispensable para el desarrollo del capitalismo en el campo. Aunque en esta ruta millones de hectáreas permanecieron estáticas o sin uso, hubo un incremento significativo de la producción y productividad en el ambiente rural, una creciente tecnificación de la agricultura, la expansión de la agroindustria brasileña y extranjera, la ampliación de la frontera agrícola al medio oeste y norte del país (frecuentemente en tierras indígenas o campesinas) y un incremento en la diferenciación social del campesinado. Aún más, el capital financie-

${ }^{7}$ El aparato estatal sufrió algunas modificaciones, como el reemplazo del IBRA e INDA por el Instituto Nacional de Colonización y Reforma Agraria (Instituto Nacional de Colonização e Reforma Agrária - INCRA-) en 1970. 
ro también interfirió con fuerza en la esfera productiva, favoreciendo la integración del capital industrial y de la banca en la esfera agrícola.

Los efectos socioambientales de esta ruta de desarrollo sobre la población rural fueron dramáticos. Entre ellos los más importantes fueron la mayor concentración de posesión de tierras, la concentración de los ingresos, la aceleración del éxodo rural (alrededor de 30 millones de personas entre 1960 y 1980), la mayor explotación de la fuerza laboral, la expansión del proceso de expropiación de los campesinos (tanto como aquellos que vivían como dependientes dentro de propiedades grandes como los productores autónomos), deterioro ambiental - expresado en erosión del suelo, deforestación y la contaminación química del suelo, agua, comida y trabajadores - y una reducción en las condiciones de vida de la mayoría de los trabajadores.

En el campo, la dictadura encarceló, torturó y asesinó a activistas de las ligas campesinas, sindicatos comunistas y la izquierda católica, al igual que intervino en los sindicatos rurales en varias formas, incluso clausurando muchos de ellos (Carneiro y Ciocari, 2010). ${ }^{8}$ Sin embargo, el régimen no logró acabar con los sindicatos ni la Contag, sin mencionar la legislación laboral. Muchos de los sindicatos que habían sido formados por la Iglesia católica para retar la influencia del comunismo y la izquierda católica fueron relativamente excluidos de la intervención, mientras que en 1965 el gobierno federal suspendió la intervención en la Contag. Gracias a las acciones de estos sindicalistas, y sobre todo de la Contag, después de 1968 resurgió una red nacional sindical, la cual se fortaleció al año siguiente (Martins, 1981; Palmeira, 1985; Medeiros, 1989; Novaes, 1991; Ricci, 1999).

En un contexto represivo, las acciones de la Contag fueron fundamentales para diseminar y enlazar referencias comunes dentro del vasto y diferenciado universo de sindicatos rurales. El legalismo que había

8 Cabe resaltar que información relevante sobre la violencia en el campo durante la dictadura es descubierta cada vez más debido al trabajo de la Comisión Nacional para la Verdad, creada por ley federal en mayo de 2012, los cuerpos estatales similares y la Comisión Campesina para la Verdad, instituidos por movimientos sociales, reabriendo una línea de investigación que parecía agotada. 
caracterizado al sindicalismo cristiano antes del golpe sobrevivió y marcó profundamente sus acciones en el siguiente periodo. ETR y el ET se usaron como instrumentos para implementar derechos laborales que los empleadores reusaban cumplir. Apelando al Poder Judicial como un espacio para resolver conflictos y hacerlos públicos, la mediación sindical significó que la ley fue aplicada más ampliamente, permitiendo un avance, lento y con muchos conflictos, en la institucionalización de relaciones entre empleadores y empleados, causando tensión en -y a veces rompiendo con - formas tradicionales de dominación. Buscando controlar a los sindicatos, la dictadura los unió al Ministerio de Trabajo, y después de 1972 usó a estas organizaciones como vehículos para la extensión de asistencia social, transformándolos en agentes de mediación para acceder a beneficios como pensión de retiro y otros beneficios, asistencia funeraria y servicios de salud, que expandieron su presencia entre los campesinos, pero también atrajeron el interés de fuerzas locales para apoyar la creación de estas entidades y mantenerlas bajo su control.

Además de la aplicación de derechos laborales, la Contag defendió el derecho a la tierra, también estipulado en la legislación, manteniendo viva de este modo la crítica al latifundio y la defensa de la reforma agraria. Mientras la modernización de la agricultura avanzaba, los campesinos fueron presionados para abandonar sus tierras. Una vez más los conflictos agrarios empezaron a incrementarse. Como resultado, la Contag recomendó medidas administrativas y legales y apeló a los miembros del Congreso y autoridades en Brasilia, pidiendo que las áreas en litigio sean expropiadas, mientras las federaciones sindicales municipales y estatales actuaban en escala local. Esta práctica consolidó un perfil activo, aunque en realidad resultó en algunos logros concretos.

El gobierno respondió a la gradual intensificación de conflictos en el campo con varias iniciativas, al igual que represión. Una de éstas fue fomentar proyectos de asentamientos para expandir la frontera agrícola en las regiones centro, oeste y norte, con el objetivo de reducir la presión 
por tierras que había empezado a crecer una vez más (Ianni, 1979; Martins, 1981, 1984).

Inscrita en el proyecto político de ocupar fronteras supuestamente «vacías», la colonización fue usada como propaganda por el Ejército como un sinónimo de reforma agraria y a menudo tuvo lugar junto a grandes proyectos de desarrollo (como autopistas, presas hidroeléctricas y de extracción de minerales). Dentro y alrededor de estos proyectos había una cada vez mayor apropiación privada de tierras públicas y tierras en posesión de campesinos y personas indígenas, frecuentemente involucrando el uso de la violencia.

En este periodo, las acciones de la Iglesia católica se hicieron fundamentales en la lucha por tierras en Brasil. Siguiendo el cambio de actitud de la Iglesia en favor de «los pobres y oprimidos», simbolizado en la Conferencia de Medellín y la Teología de la Liberación, se llevaron a cabo varias iniciativas para impulsar transformaciones en el ambiente rural. En particular, el papel de la Comisión Pastoral de Tierra (Comissão Pastoral da Terra - CPT-) fue de gran importancia. Fundada en 1975, estaba involucrada en la denuncia, mediación y la vocalización y organización de los grupos sociales sometidos a condiciones de explotación y violencia. Basándose en lecturas bíblicas, condenó la propiedad privada con propósitos de ganancia y especulación. En 1980, esta visión fue formalizada en un documento por la Conferencia Nacional de Obispos de Brasil (Conferencia Nacional dos Bispos do Brasil - $\mathrm{CNBB}-$ ) que condenó la «tierra de negocios» en defensa de la «tierra de trabajo» (sin recurrir a la explotación del trabajo ajeno).

Al final de los años setenta y al inicio de la siguiente década, las luchas sociales en el campo tomaron una nueva configuración y magnitud. La modernización de la agricultura y las otras políticas implementadas por el régimen de excepción habían producido o acelerado transformaciones profundas en el mundo del trabajo y la vida social, al mismo tiempo que los canales existentes de unión o representación política no eran capaces -o suficientes - para procesar y dirigir las demandas. Después de las luchas se formaron nuevos sujetos sociales, 
como los atingidos por barragens (víctimas de las represas), seringueiros (extractores de goma), los sin tierra, trabajadores rurales y pequeños granjeros (Martins, 1984; Medeiros, 1989).

En particular, el sindicalismo rural fue presionado desde dentro y desde fuera. La Contag fue criticada cada vez más por su excesivo legalismo, por no estimular una movilización y organización de base, por su baja capacidad de ejercer presión y por el asistencialismo de muchos sindicatos. El liderazgo de muchos sindicatos fue disputado por grupos de oposición, que propusieron nuevas formas de lucha. CPT y sindicatos cercanos a la Teología de Liberación fueron agentes importantes en la crítica del sindicalismo tradicional. Esas disputas originaron dos efectos importantes: por un lado, la Contag tuvo que adaptarse. En 1979, la organización reafirmó la reforma agraria que tenía como su principal eslogan «variada, general, masiva, inmediata y con la amplia participación de los trabajadores». Por otro lado, las disputas dentro la Contag estaban conectadas con el movimiento que era crítico de la estructura sindical corporativista y de las prácticas de esa época en el sindicalismo en su conjunto, conocido como «nuevo sindicalismo.» En 1983, de este movimiento surgieron la Central Única de Trabajadores (Central Única dos Trabalhadores - CUT-) - estrechamente relacionada con el Partido de los Trabajadores (Partido dos Trabalhadores - PT -), fundado en 1980 - y los muchos sindicatos rurales vinculados con ella, igualando sindicatos en disputa con la Contag. ${ }^{9}$ En 1986, la cu t creó la Secretaría Nacional de Trabajadores Rurales (Secretaria Nacional dos Trabalhadores Rurais), dos años después se transformó en el Departamento Nacional de Trabajadores Rurales (Departamento Nacional dos Trabalhadores Rurais - DNTR-), para organizar a los sindicatos «Cutistas» (Medeiros, 2010).

En el mismo contexto, en 1984 se fundó el Movimiento de Trabajadores Rurales Sin Tierra (Movimiento dos Trabalhadores Rurais Sem

9 La base del nuevo sindicalismo consistía en la defensa de la libertad y autonomía en relación con el control del Estado. Por otro lado, la Contag defendía el mantenimiento de unicidad sindical (un sindicato por categoría profesional por municipio), como establecía la legislación. 
Terra - MST-). Resultando de una confluencia de procesos económicos y experiencias sociales, el MST pronto se distinguió por el énfasis que daba a las ocupaciones de tierra, que movilizaban a familias enteras ( $y$ no sólo la cabeza de familia), no requería ningún tipo de afiliación formal (a diferencia de los sindicatos) y cuyo objetivo era presionar al Estado para expropiar propiedades rurales y asentar a las familias movilizadas, con la negociación con el Estado, basada en presión colectiva y no a través de arreglos legales o acuerdos entre líderes. «La tierra no se obtiene, se gana» y «la ocupación es la única solución» eran los eslogans que se evocaban entonces. Basándose en ocupaciones, el MST desarrolló métodos de organización que darían forma a su propia identidad política (véase Caldart, 2000; Fernandes, 2000; Carter, 2014).

\section{CRISIS DE LA DICTADURA Y TRANSICIÓN DEMOCRÁTICA} (1979-1989)

El inicio de la transición democrática en Brasil tuvo lugar en medio del giro neoliberal internacional dirigido por Estados Unidos, la crisis de la deuda externa que explotó en 1982 y la subsecuente adopción de programas de ajuste estructural por el Banco Mundial y el Fondo Monetario Internacional (FMI). El colapso del modelo económico y la administración de la crisis impactó negativamente en la economía brasileña durante los años ochenta. Rápidamente, el centro de atención de la política económica se dirigió a la reducción del déficit en transacciones corrientes, a través de la generación de grandes cantidades de excedentes en el balance de pagos comerciales, principalmente mediante la exportación de productos primarios. Entonces los balances comerciales se convirtieron en las fuentes principales de cambio de divisas del gobierno para transferir a acreedores extranjeros.

La política de devaluación monetaria compensó, en moneda brasileña, la pérdida de ingresos en dólares de los exportadores brasileños causada por la caída en los precios internacionales de productos agrícolas, lo que garantizó un incremento en la producción durante la década. 
Al mismo tiempo, los subsidios al sector agrícola continuaron siendo significativos, aunque más selectivos, priorizando cadenas agroindustriales determinadas (como azúcar alcohol y trigo). Finalmente, casi hasta el final de los años ochenta, el sector agrícola se benefició del mantenimiento de tasas de interés real negativas (Leite, 2001:60). En otras palabras, la acción del Estado en el sector agrícola ocurrió en una forma aún mucho más efectiva en favor de algunos agentes económicos grandes, a costo de la estrangulación financiera del Estado mismo.

Mientras el modelo económico entraba en colapso, en el campo y las ciudades la presión popular se incrementaba no sólo para el retorno del régimen democrático, sino para la democratización social efectiva. Los límites de la transición se hicieron visibles con el «pacto desde arriba» que derrotó la campaña por elecciones directas para presidente en 1984 (Fernandes, 1985).

A pesar de los límites del proceso en curso, la coalición gubernamental terminó incorporando fuerzas políticas heterogéneas e incluso contradictorias. Por lo tanto, dado el drama de la violencia en el campo, ${ }^{10}$ el incremento en conflictos y movilizaciones campesinas, en 1985 el gobierno federal creó el Ministerio de Reforma y de Desarrollo Agrario (Ministério da Reforma e do Desenvolvimento Agrário - Mirad-). Nelson Ribeiro, vinculado al sector progresista de la Iglesia católica, fue puesto a cargo del mirad y nominó a José Gomes da Silva, fundador de la Asociación Brasileña de Reforma Agraria (Associaçâo Brasileira de Reforma Agrária - ABRA-) y uno de los redactores del ET, como presidente del INCRA.

En mayo de 1985, durante el cuarto congreso de la Contag, el Presidente la República propuso el Plan Nacional de Reforma Agraria (Plano Nacional de Reforma Agraria - PNra-). Al mismo tiempo que se selló el apoyo de la Contag al gobierno, el anuncio hizo parecer que había llegado la hora de la reforma agraria (D'Incao, 1990; Graziano da

${ }^{10}$ En 1985 fueron asesinados 211 campesinos y arrestados 326. Entre 1979 y 1988 fueron asesinadas 1,304 personas involucradas en la lucha por las tierras, según ABRA. 
Silva, 1985; Gomes da Silva, 1987). ¿Qué se propuso?: la expropiación como el instrumento principal para obtener tierras, en lugar de un recurso excepcional; el pago por indemnización de tierras expropiadas estaría basado en el valor de la propiedad declarado por los propietarios para propósitos impositivos; ${ }^{11}$ la centralidad del programa de asentamientos para las familias sin tierra, relegando otras acciones (como la colonización, el otorgamiento de títulos y tasación) a medidas complementarias; el establecimiento de un objetivo de asentamientos de $7 \mathrm{mi}$ llones de los estimados 10.5 millones de campesinos sin tierra o con tierras insuficientes en un periodo de 15 años; el establecimiento de «áreas prioritarias» para la reforma agraria, en las cuales había una concentración de asentamientos que rompieron con el patrón de intervención ocasional en focos de conflicto; la participación de organizaciones que representaban a los trabajadores rurales en todas las fases del proceso.

El mst estaba en contra de la propuesta. Cuatro meses antes, en su primer congreso, ya había propuesto una reforma agraria «bajo el control de los trabajadores», involucrando la expropiación de todas las propiedades rurales arriba de 500 hectáreas, la inmediata redistribución de tierras públicas y la expropiación de tierras de las compañías multinacionales. Más aún, en la misma ocasión, el MST condenó al ET como un instrumento legal creado por la dictadura para modernizar el latifundio, considerándolo no apto para hacer la reforma agraria factible. Esta posición fue compartida por la CUT. Cuando la propuesta del PNRA se anunció, el MST llevó a cabo una serie de ocupaciones en el sur del país, buscando no sólo afirmar independencia del gobierno, sino también consolidar sus posiciones como el principal portavoz de los sem terra y la causa de la reforma agraria.

A su vez la Contag, aun cuando apoyó la propuesta, criticó los límites del ET, sin embargo, creía que renunciar a ellos resultaría en un vacío legal perjudicial. Algunas de las resoluciones del cuarto congreso también

11 Ya que esta declaración siempre era mucho menor que el valor de mercado para que de ese modo el impuesto sea más bajo, la medida significaba que los propietarios serían penalizados por no cumplir la «función social» de la propiedad, como estaba estipulado en el Estatuto de Tierras. 
se apartaron de los parámetros establecidos por la legislación que estaba en vigor. Una de éstas era la propuesta de expropiar empresas rurales; otra era el pago de mejoras en TDAs; también se demandó la preparación de una nueva ley de reforma agraria para ser presentada a la futura asamblea constituyente (Medeiros, 1989: 170). Sin embargo, como parte del apoyo al gobierno, la Contag descartó llevar a cabo ocupación de tierras.

En el PNRA se propuso enfatizar el uso de expropiación a través de pagos compensatorios en TDAs y bajo el valor declarado por los propietarios con fines de recolección de ingresos - lo que redujo el valor de las indemnizaciones en 60 por ciento-(Gomes da Silva, 1987: 65). Éste había sido el punto central de los conflictos políticos en vísperas del golpe de 1964 y dos décadas después regresó a la palestra. Sin embargo, los tiempos eran diferentes. El punto central de la propuesta era la expropiación de latifundios «improductivos», mantenidos con propósitos de especulación, de acuerdo con una visión productivista que perdonaba los latifundios «productivos». Se esperaba que la fuerza de los propietarios «atrasados» sería menos que en los años sesenta, debido a la modernización de la agricultura. Sin embargo, fue en el sureste, particularmente en el estado de São Paulo - el más rico e industrializado del país - donde surgió la reacción más intransigente contra la propuesta (Veiga, 1990: 130). Como uno de los involucrados en ese tiempo dijo: "precisamente porque disparamos directamente contra la especulación, impactamos el corazón del sistema» (Palmeira, 1994: 56).

Los grandes vehículos de comunicación iniciaron su campaña antireformista, con la intención de aterrorizar a la población con la idea de una inminente «convulsión social» en el campo y el «caos» en agricultura, acusando a la propuesta «socialista» de pretender «confiscar la propiedad privada» (Veiga, 1990: 82; Gomes da Silva, 1987: 74).

La Confederación Nacional de Agricultura y Pecuaria de Brasil (Confederação Nacional da Agricultura e Pecuária do Brasil - CNA- $)^{12}$ tuvo

12 Creado en enero de 1964, el CNA era parte de la estructura del sindicato corporativo en el país por parte de los empleadores. Esta estructura consiste en más de 2,000 sindicatos de empleadores rurales con una base municipal, representados por 27 federaciones estatales (una en cada estado). 
un congreso poco después de la propuesta, demandando al final el despido del ministro Ribeiro. Sin embargo, durante el congreso surgieron diferencias con un grupo asumiendo la inevitabilidad de la reforma agraria y buscándose anticipar y dirigir el proceso según sus intereses, contra otro grupo, que estaba radicalmente en contra de la ocupación de tierras y muchas otras propuestas de la reforma (Bruno, 1997: 51). De este grupo nació la Unión Democrática Ruralista (União Democrática Ruralista - UDR - ), uniendo principalmente a rancheros del sureste y centro oeste (Mendonça, 2011: 61). Rápidamente, la UDR se hizo un nombre para sí misma en el escenario internacional al llamar a los propietarios a armarse contra las ocupaciones de tierra. Con su defensa intransigente de la propiedad, la entidad logró organizar a propietarios de todo el país - modernos y atrasados, grandes, medianos y pequeños-. Con el objetivo de garantizar libertad de acción, la UDR no se institucionalizó como las otras entidades de empleadores, disputándose con éstas la condición de ser el principal portavoz de los «los productores rurales» en el país (Dreifuss, 1989: 69; Bruno, 1997: 56).

La categoría «productor rural» surgió en el vocabulario político durante este periodo como un instrumento de combate y la formación de identidad social, buscando sustituir la imagen negativa del latifundista, con una positiva asociada con la imagen genérica de producción. Por tanto, la referencia al monopolio privado de la tierra se suprimió. Ocultando la desigualdad entre propietarios, la categoría forjó una horizontalidad falsa entre los productores. Las entidades empleadoras diseminaron el discurso de competencia técnica y eficiencia económica, presionando al gobierno federal con políticas agrícolas adecuadas.

Las presiones fueron tan intensas que entre mayo y octubre de 1985, cuando se aprobó la versión final del PNRA, la propuesta original había sido modificada significativamente después de 12 versiones. ${ }^{13}$ Las posi-

\footnotetext{
${ }^{13}$ Las principales modificaciones fueron: un énfasis en la negociación con los propietarios en lugar de expropiación, transformando la expropiación en una medida excepcional y por tanto minando la idea de la penalización del latifundio; la imprecisión en la definición de propiedad productiva, preservando todos los latifundios, ya sea por exploración o extensión, una vez que una pequeña parte ha
} 
ciones del ministro y el presidente del INCRa fueron minadas, resultando en sus renuncias. En esta ocasión se instituyeron varias normas legales que restringían aún más el proceso de expropiación, como el Decreto número 2.368/87 que eximió de expropiación a «áreas en producción», sin considerar su tamaño (Ferreira et al., 2009: 162). En 1989 se cerró MIRAD. En relación con la implementación del PNRA, el objetivo de asentamientos para 1985-1989 era de 1'400,000 familias en 43’090,000 hectáreas. Sin embargo, sólo se obtuvo 10.5 por ciento de las tierras y sólo 6.4 por ciento de las familias se asentaron (Leite y Ávila, 2007: 83).

Después del fracaso del PNRA, las organizaciones campesinas movieron sus energías a las disputas en la Asamblea Nacional Constituyente (1987-1988). De hecho, el tema de la «reforma agraria» condensó los conflictos de clase más amargos en todo el proceso legislativo. Varias organizaciones estuvieron involucradas en la Campaña Nacional por la Reforma Agraria, ${ }^{14}$ proponiendo una enmienda popular para la cual se recolectaron más de un millón doscientas mil firmas. El corazón de la propuesta constituía la idea de la «función social» de la propiedad, no cumplir con ésta podría resultar en sanciones yendo de la pérdida sumaria de la propiedad a la compensación por el valor declarado con fines fiscales. También se propuso el establecimiento de un límite máximo de propiedad que un individuo o compañía podría poseer, para ser calculado según parámetros regionales.

Los grupos de empleadores también se movilizaron. Por ejemplo, la UDR realizó marchas, concentraciones, campañas de propaganda en escuelas y universidades, publicitando en los medios de comunicación,

estado en producción (de ese modo surgió la bizarra figura judicial de latifundio productivo); el empobrecimiento de la discusión sobre la función social de la propiedad, dado el énfasis en si la tierra era productiva o no; la exención de la expropiación de propiedades rurales donde había una gran incidencia de parceria y contratos de arrendamento - contradiciendo la lectura del ET y las demandas de las organizaciones campesinas, que condenaban estas relaciones como expresiones de la explotación del trabajo y las fuentes de conflicto-; y la no definición de áreas prioritarias de reforma agraria (véase Fachin, 1985; Graziano da Silva, 1985; Gomes da Silva, 1987).

${ }_{14}$ En total la propuesta fue acordada por 17 entidades, incluyendo Contag, CNBB, CUT y ABRA. 
cooptó líderes locales y presionó al Congreso, al igual que organizó milicias en propiedades amenazadas por la «invasión» (Dreiffus, 1989; Bruno, 2008). Por otro lado, para desligarse de la imagen de truculencia de la UDR y para disputarse la hegemonía entre los empleadores rurales, la OCB $^{15}$ patrocinó el Frente Amplio de Agropecuária Brasileña (Frente Ampla da Agropecuária Brasileira - FAAB-), involucrando a la CNA y SRB. Al final la FAAB y la UDR convergieron en la defensa incondicional del «derecho a la propiedad» y la «libre empresa» para bloquear cualquier posibilidad de reforma, con el apoyo de representantes de negocios industriales urbanos y el capital internacional. Como en los años sesenta, no hubo evidencia de apoyo desde los sectores "progresivos»y «modernos» de la burguesía brasileña para la reforma agraria.

Aunque la constitución de 1988, debido a presión popular, había expandido la esfera de derechos ciudadanos en Brasil, ${ }^{16}$ no se podía decir lo mismo en relación con la democratización del acceso a la tierra. Por primera vez la expresión «reforma agraria» apareció en un texto constitucional y se definió que la propiedad debía cumplir su «función social», entendida como uso racional, adaptada a los recursos naturales y a la preservación del medio ambiente, el cumplimiento de la legislación laboral y explotación que favorezca el bienestar de los trabajadores y propietarios. Sin embargo, la definición de los criterios de cumplimiento con la función social permaneció ambigua (con la excepción de referencias a la legislación laboral). Todas las referencias al latifundio fueron borradas del texto, no se estableció un límite máximo para la posesión

${ }_{15}$ Fundada en 1969 por personas de São Paulo, la Organización de Cooperativas Brasileñas (Organização das Cooperativas Brasileiras - Осв-) se convirtió en la única entidad representativa nacional del cooperativismo agroindustrial después de la Nueva Ley de Cooperativismo de diciembre de 1971. Tomando ventaja de sus relaciones con la dictadura, se benefició de acuerdos con cuerpos públicos que le proporcionaron recursos decisivos para su ascenso. Usando hábilmente la ideología de democracia e igualitarismo entre cooperativas de varios tamaños, jugó un papel fundamental en la construcción del proyecto político de la modernización empresarial y la internacionalización de los agronegocios brasileños durante los años noventa (véase Mendoça, 2011).

16 Con la expansión, entre otras medidas importantes, del derecho al voto a los analfabetos. 
de tierras, y los trabajadores asentados no se definieron como un público prioritario para la política agrícola, en contraste con lo que las organizaciones campesinas habían exigido. Más aún, la decisión sobre posesión de tierras con propósitos de expropiación permaneció con el Poder Judicial, permitiendo retrasos legales y, por tanto, retrasando la creación de asentamientos.

En relación con las expropiaciones, se establecieron compensaciones por adelantado y justas en TDAs, canjeables hasta en 20 años, después del segundo año, con la preservación garantizada del valor real. De esta forma, se fortaleció la tendencia de remunerar a los propietarios con base en valores de mercado, recompensando en lugar de castigar a los propietarios que no cumplieron con la función social. ${ }^{17}$

El texto constitucional previno la expropiación de propiedades rurales pequeñas y medianas (menos de 15 módulos fiscales), ${ }^{18}$ al igual que propiedades productivas. Se suponía que la «propiedad productiva» sería regulada en legislación complementaria, la cual sólo sería promulgada cinco años más tarde. Mientras tanto, el vacío legal hizo las expropiaciones irrealizables.

Siguiendo la aprobación de la Ley Agraria en febrero de 1993, los modestos mecanismos constitucionales de reforma agraria fueron regulados, sin embargo, sólo en relación con los aspectos económicos, por lo tanto, haciendo irrealizable la expropiación por motivos sociales y ambientales.

Más aún, a diferencia de la expropiación por utilidad pública (pagada en dinero), en la cual el propietario sólo podría cuestionar el valor de la compensación en las cortes, en el caso de expropiación para

17 Esta tendencia empeoró después de 1995, cuando los TDAs fueron aceptados como medios de pago en la privatización de compañías públicas, siendo convertidos en una moneda paralela y bien financiero con buena liquidez.

${ }_{18}$ El modelo fiscal es una unidad de medida expresada en hectáreas. Fue establecido para cada municipalidad tomando en cuenta varios criterios y sirvió como un parámetro para la clasificación de la propiedad rural en términos de su tamaño de la siguiente forma: a) minifundio (menos de un módulo); b) propiedad pequeña (entre uno y cuatro módulos); c) propiedad mediana (entre cuatro y 15 módulos); d) propiedad de grande (arriba de 15 módulos). 
propósitos de reforma agraria el dueño de la propiedad podía cuestionar el mérito del caso, lo que le permitiría manipular los procedimientos en su favor y retrasar el inicio del proceso de asentamientos por un periodo indeterminado, o en casos extremos revertir la expropiación, incluso después de la creación de asentamientos.

La legislación estableció mecanismos que atribuyeron al Poder Judicial la autoridad de toma de decisiones en varios puntos de la puesta en práctica de cualquier política de tierras, creando condiciones para la creciente judicialización de la cuestión agraria. Esto resaltó el hecho de que la predominante socialización jurídica entre los operadores de la ley en Brasil estaba - y aún está - en la visión del derecho de la propiedad como algo inviolable y absoluto (Fachin, 1993), lo que alimentó una postura desfavorable para los sin tierra entre la mayoría de los jueces, presidiendo juicios que involucraban conflictos agrarios en el campo.

La correlación de fuerzas institucionalizadas en la constitución de 1988 y en la legislación subsecuente minó la posibilidad de implementar una reforma agraria a gran escala en Brasil. El marco legal permitió como mucho una política de asentamientos limitada, susceptible de fluctuaciones cíclicas.

Después de la lucha constitucional, el siguiente capítulo en la lucha de clases en Brasil fue la elección presidencial de 1989. Durante la campaña electoral, de 22 candidatos, la disputa terminó polarizada entre Collor de Mello y Lula da Silva. Los movimientos populares retornaron a las calles, al mismo tiempo que las huelgas explotaron por todo el país, demandando reformas sociales profundas. Mientras tanto, el sector de negocios y el Ejército usaron lemas como anticomunismo, la modernización del campo, la lucha contra la corrupción y los "privilegios» de los empleados públicos. Se organizó una campaña de terrorismo ideológico para crear la idea de que el país estaba experimentando una «guerra interna» (Dreifuss, 1989: 266-294). El resultado electoral representó la derrota de un proyecto popular democrático alimentado por una década de lucha en el campo y las ciudades. Al mismo tiempo la guerra fría terminó y surgió el Consenso de Washington. 


\section{ADMINISTRACIONES DE COLLOR E ITAMAR (1990-1994)}

El gobierno de Collor (1990-1992) introdujo el neoliberalismo en Brasil. Entre otras medidas, implementó una política económica que empeoró severamente las condiciones de vida y empleo en el campo y las ciudades. A nombre de la lucha contra los privilegios en la administración pública y la modernización administrativa, el desmantelamiento del modelo de intervención estatal en la agricultura, que había estado en uso desde 1980, se llevó a cabo a través de la reducción drástica del volumen de recursos para política agrícola, la finalización de la política de reservas públicas de alimentos, apertura comercial unilateral y el cierre de Embrater. El INCRA fue prácticamente paralizado debido a la ausencia de recursos y el latifundista vinculado a la UDR fue designado como su cabeza.

El tratamiento a las luchas populares se resumió en represión y criminalización. Aún más, este gobierno no hizo ninguna expropiación nueva con fines de reforma agraria debido a la falta de voluntad política y a la ausencia de la regulación de medidas constitucionales. A su vez, los asentamientos existentes fueron abandonados a su propia suerte (Medeiros, 2002; Ferreira et al., 2009).

Durante la administración de Itamar (1992-1994) hubo una inflexión en el trato de los movimientos sociales en el campo. Por primera vez un presidente brasileño se reunió con representantes del MST, reconociendo a la organización como un interlocutor legítimo. Personas que habían estado involucradas y tenían credibilidad con movimientos sociales fueron designadas al comité del Incra a inicios de 1993. Más aún, después de la aprobación de la Ley Agraria en mayo de ese mismo año, las modestas medidas constitucionales relacionadas con ésta fueron reguladas, permitiendo que se lleven a cabo expropiaciones. La cuestión retomó espacio en la agenda gubernamental debido a la presión de los movimientos sociales y debido a su asociación con la lucha contra el hambre. Sin embargo, en el contexto de la implementación del Plan Real (el programa de estabilización monetaria), gran cantidad de presión política dentro y fuera del gobierno minó la ejecución de este 
tímido programa de «reforma agraria». Sólo 23,000 familias se asentaron en 152 proyectos (Stédile y Fernandes, 1999; Medeiros, 2002; Ferreira et al., 2009).

\title{
GOBIERNO DE CARDOSO Y CUESTIÓN AGRARIA
}

(1995-2002)

\begin{abstract}
Al frente de un proyecto radical de transnacionalización de la economía brasileña, el gobierno consideró al gran volumen de capital en el mercado financiero internacional como un sinónimo del final de la restricción externa que marcó al capitalismo dependiente. Como resultado se abandonó la política de crear balances comerciales en la década previa (Delgado, 2010: 92). Por un lado, la enorme liquidez internacional, el mantenimiento de altas tasas de interés internas y la sobrevaluación de la moneda practicada hasta 1998 -los tres pilares del «éxito» del Plan Real一, combinadas con la liberalización comercial unilateral y el desmantelamiento del modelo regulatorio agrícola, provocaron efectos drásticos en el sector agrícola brasileño. El volumen de importaciones agrícolas se disparó, llegando a niveles sin precedente (Delgado, 2009: 20). Por otro lado, el declive acelerado de los precios agrícolas no fue contrabalanceado por las políticas de apoyo a los precios, impactando severamente a los ingresos agrícolas y llevando a varios establecimientos a la bancarrota.

La reforma agraria sólo apareció en forma lateral en las elecciones de 1994. Sin embargo, los candidatos principales (Lula y Cardoso) estaban a favor de la medida, pero le dieron un contenido distinto (Carvalho, 2001). El programa de Lula la percibió como una política con una naturaleza estructural y propuso el asentamiento de 800,000 familias sin tierra en cuatro años, aunque fue vago sobre el origen de los recursos para esto. La expropiación figuró como el principal instrumento de redistribución de tierras. Por otro lado, el programa de Cardoso prometió asentar a 280,000 familias en cuatro años, sin ninguna pretensión de cambio estructural, lidiando con la cuestión en una forma bienestarista, como un medio de aliviar la pobreza rural.
\end{abstract}


Sin embargo, la convergencia de tres factores entre 1995-1997 ayudó a modificar el escenario agrario. El primero era la repercusión nacional e internacional de la violencia policiaca en acciones contra campesinos en Corumbiara (agosto de 1995) y más específicamente en Eldorado dos Carajás (abril de 1996). Ambos episodios resultaron en docenas de campesinos muertos y alimentaron una serie de protestas en Brasil y el extranjero en contra de la violencia del campo y en favor de la reforma agraria.

El segundo factor fue el incremento en las ocupaciones de tierras prácticamente en todo el país. El MST fue la principal fuerza organizacional en este proceso, pero en algunos estados los sindicatos unidos a Contag también cumplieron este papel, en particular ocupaciones en Pontal do Paranapanema - una región caracterizada por el grilagem (reclamo ilegal de tierra) de tierras públicas en el estado de São Paulo-. Varios líderes del MST fueron arrestados y se incrementaron las tensiones sociales con la violencia de la policía y grupos armados al servicio de los latifundistas.

Otro factor decisivo fue la celebración de la exitosa Marcha Nacional por la Reforma Agraria, Empleo y Justicia. Organizada por el MST, la marcha duró tres meses, partiendo desde varias partes del país y alcanzando la capital el 17 de abril de 1997, un año después de la masacre en Eldorado dos Carajás. La marcha logró ganar la simpatía de una parte de la opinión pública urbana. Junto con los «sin tierra» estaban los «sin techo»y «desempleados», entre otros, juntando alrededor de 100,000 personas en las calles de Brasilia en la primera demostración masiva contra las políticas neoliberales.

Estos eventos no sólo dieron una gran visibilidad a las ocupaciones de tierra y las demandas por reforma agraria, también propulsó al MST a la prominencia en los escenarios políticos nacionales e internacionales. En este punto, este movimiento ya no podía ser tratado como un simple «caso policial», ni se podían ignorar sus demandas.

La respuesta del gobierno federal vino poco después de la masacre de Eldorado dos Carajás, con la creación del Ministerio Extraordinario 
de Política de Tierras (Ministério Extraodinario de Política Fundiária - MEPF-). El MEPF se encargó de la responsabilidad del INCRA — hasta que se subordinó al Ministerio de Agricultura- y ambos estaban relacionados directamente a la Presidencia de la República (Medeiros, 2002). El MEPF inició una serie de iniciativas dirigidas a reducir la tensión en el campo y debilitar el surgimiento político del MST.

En primer lugar, en 1996 se tomaron medidas para alterar el impuesto territorial rural (imposto territorial rural — ITR - ), argumentando que la reforma agraria se lograría a través de la tributación progresiva. Sin embargo, debido a la fuerza política de los latifundistas en el Estado esto no sucedió, mientras la evasión fiscal permaneció muy alta (90 por ciento en 1997).

Segundo, en 1997 se promulgaron una serie de medidas para hacer más rápido el proceso de expropiación, para reducir las compensaciones pagadas a los dueños y acelerar el asentamiento de familias (MEPF, 1998). No todas se aplicaron y algunas no tuvieron efectos relevantes, pero se mostró que el gobierno estaba preocupado por acelerar su capacidad de responder la presión social (Medeiros, 2002).

En tercer lugar, comenzó la desfederalización de la reforma agraria, transmitiendo a los estados y municipios la competencia de conducir procesos para acceder a tierras y asentamientos, por tanto convirtiéndolos en objetos de regateo negociado localmente (MEPF, 1997). Esta política estaba en contra de la posición de todas las organizaciones campesinas. Más aún, estaba combinada con otras medidas, permitió la incorporación de organizaciones sindicales y excluyó al MST de la participación en algunas políticas públicas, dividiendo el universo de organizaciones campesinas y estimulando su operación manual.

Estas iniciativas tuvieron lugar en un contexto de represión de luchas sociales en el campo, en las cuales la policía federal se usó para monitorear a los sin tierra, se llevaron a cabo desalojos de una forma truculenta e ilegal. Incluso la derecha agraria extrema empezó a reformarse en algunas regiones, movilizando instrumentos privados de violencia, reforzados frecuentemente por el Poder Judicial estatal y la policía (Carvalho, 
2001). Los grupos de negocios empezaron a defender el uso de la fuerza contra las ocupaciones.

Al mismo tiempo, los principales medios de comunicación empezaron a diseminar una imagen positiva de la administración de Cardoso en relación con la reforma agraria y una imagen negativa de los movimientos sociales, en particular el MST. En general, los medios eran afines a los datos oficiales que resaltaban - y también inflaban- el incremento en el número de familias asentadas, mientras el MST era asociado con disturbios, violencia, corrupción y una falta de vocación por la agricultura.

Finalmente, el gobierno inició la «reforma agraria asistida por el mercado» (RAAM). Propagada por el IRBD, esta propuesta prescribió la concesión de préstamos a los campesinos pobres para comparar tierras negociadas en forma voluntaria y directa con los dueños. Para esta transacción los dueños deberían ser pagados previamente en dinero al precio de mercado, mientras los compradores asumían los costos de la adquisición de tierras. Junto con el préstamo, los compradores recibieron un monto variable de subsidios para inversiones en infraestructura y producción. Este mecanismo permitió el regateo de propiedades, ya que a más bajo el precio de la tierra, más fondos quedaban para inversiones (Van Zyl y Binswanger, 1996). En otras palabras, el MALR fue una operación para comprar y vender tierras entre agentes privados financiados por el Estado, con la adición de un subsidio variable. Políticamente, este modelo era parte de las estrategias del IBRD para aliviar la pobreza rural, complementario a las políticas de ajuste macroeconómico.

Según los especialistas del IBRD, Brasil ofrecía condiciones ideales para el MALR, debido a una política económica que estaba en ejecución, lo cual impactó regresivamente en el tejido social rural, existió una enorme demanda por tierras y una tendencia a caer en los precios de propiedades rurales de algunas regiones. A su vez, en el lado del gobierno era necesario responder al incremento en la presión social por tierras, pero también guió la forma en que la cuestión agraria debía procesarse política e institucionalmente. Fue esta convergencia de intereses lo que permitió la posibilidad de introducir al MaLr en Brasil (Pereira, 2007). 
El primer proyecto de este tipo empezó en agosto de 1996 en el estado de Ceará. De esta pequeña experiencia nació el proyecto piloto Banco de Tierras Cédula da Terra (РСт), extendido a otros cuatro estados en un nuevo préstamo aprobado por el IBRD en abril de 1997. El PCT financiaría la compra de tierras para 15,000 familias en cuatro años, pero la expectativa era financiar después a un millón de familias en los próximos seis años (IBRD, 1997). Se escogió como objetivo la región noreste, ya que la población pobre rural del país estaba concentrada ahí. De este modo, dada la creciente «demanda» de tierras, se estima que su implementación tendría lugar rápidamente. El proyecto financió la compra de cualquier propiedad rural, incluyendo aquellas que podrían ser expropiadas, y fue criticado por el MST y la Contag como una expresión de neoliberalismo e incapaz de democratizar la estructura agraria.

Entretanto, la mayoría gubernamental en el Congreso aprobó la creación en febrero de 1998 del Banco de Tierras, un fondo público capaz de juntar fondos de diversas fuentes, incluso internacionales, para financiar la compra de tierras por los campesinos pobres y los sin tierra (MEPF, 1999). En otras palabras, sin ninguna evaluación de las experiencias en curso y en contra de la posición de todos los movimientos campesinos, el Congreso aprobó la creación de un instrumento para implementar MALR a nivel nacional.

El gobierno federal hizo un uso intensivo de propaganda para divulgar las supuestas ventajas del nuevo modelo, mientras al mismo tiempo se criminalizaban las ocupaciones de tierra. Basada en la idea de acceso «negociado» $y$ «sin conflictos», la propaganda estaba dirigida al público movilizado en ocupaciones y campamentos, al igual que a los que podrían potencialmente movilizarse.

$\mathrm{Al}$ mismo tiempo, en respuesta a la presión de los movimientos sociales que demandaban una política de educación en asentamientos de la reforma agraria, en abril de 1998 el gobierno federal creó el Programa Nacional de Educación en Reforma Agraria (Programa Nacional de Educação na Reforma Agrária - Pronera-), dirigido inicialmente a la educación de personas jóvenes y adultos, después sus actividades fueron 
extendidas a educación técnica y fundamental, secundaria y niveles altos de educación. Sin embargo, se destinaron pocos recursos para financiarla.

El segundo mandato de Cardoso empezó en 1999 con la crisis del Plan Real y la adopción de un programa de ajuste fiscal acordado con el FMI. En este contexto, la política de ajuste externo se ajustó una vez más. De regreso a la estrategia adoptada en 1994, una vez más se implementó una política de generación de balance comercial externo para satisfacer el déficit de cuenta corriente. Como había ocurrido en la crisis de 1982, se llamó a los sectores exportadores de productos primarios para generar este balance. En ese momento, una palabra hizo eco con fuerza en los medios tradicionales: agronegocios, un término genérico creado y diseminado por organizaciones de empleadores - especialmente ABAG-, ${ }^{19}$ y entonces agronegocios se elevó a la oposición de «salvador» de la economía brasileña. Sin embargo, en una interpretación crítica agronegocios señalaba «una asociación de capital agroindustrial grande con grandes propietarios. Esta asociación hizo una alianza estratégica con el capital financiero, persiguiendo ganancias e ingresos de la tierra bajo el auspicio de las políticas estatales» (Delgado, 2010: 93).

La estrategia adoptada por el gobierno consistía en una combinación de cuatro iniciativas: $a$ ) inversión prioritaria en infraestructura territorial, medios de transporte y rutas para transportar la producción al extranjero; b) la reorganización del sistema público de investigación agrícola para armonizar con las grandes empresas agroindustriales; c) baja regulación del mercado de tierras, para permitir el control privado de los recursos de tierra necesarios para la expansión de la agricultura; d) devaluación monetaria que elevó la rentabilidad de los sectores exportadores (Delgado, 2010: 94).

${ }^{19}$ La Asociación Brasileña de Agronegocios (Associação Brasileira de Agribusiness - ABAG-) fue creada en 1993 por los líderes de la осв con el fin de juntar a todos los grupos de empleadores rurales. Jugó un papel central difundiendo la noción de agronegocios como un sector de la economía marcado por atributos como vocación, excelencia técnica y modernidad. La ABAG involucró a varias entidades, como los bancos públicos y privados y los vehículos de comunicación más grandes en el país, lo que ilustra cuánto se han expandido los agronegocios (Mendoça, 2011: 214). 
Junto con esa estrategia, el gobierno se concentró en: a) descentralizar el programa de reforma agraria a los estados y municipios; $b$ ) subcontratar y privatizar servicios técnicos de actividades ligadas a los asentamientos (como la asistencia técnica); c) dar a los colonos titularidad de sus tierras en tres años, para hacerles pagar por la propiedad rural expropiada; d) transferir a los colonos la responsabilidad de varias atribuciones sobre las que el INCRA había tenido jurisdicción previa (como la topografía, marcado de lotes, etcétera); e) mantener el programa de reforma agraria como una política para aliviar la pobreza rural, sin ninguna intención de cambio estructural; $f$ ) reprimir la ocupación de tierras y estrangular económicamente al MST, prohibiendo la liberación de recursos públicos para las actividades que realizaba; $g$ ) implementar MALR a gran escala, a través del Banco de Tierras (véase MEPF, 1999 y 1999a; Alentejano, 2000).

Debido a la represión de las luchas por tierras y la implementación del MALR, los movimientos campesinos vieron una unidad política más grande en el Foro Nacional de Reforma Agraria y Justicia en el Campo. ${ }^{20}$ En octubre de 1998, el Foro envió una solicitud de investigación al panel de investigación del IBRD, con una serie de críticas y acusaciones contra el рст. En mayo de 1999, el panel encontró que todos los argumentos del Foro eran infundados y no recomendó a la junta del IBRD que se lleve a cabo la investigación solicitada. El gobierno brasileño usó esto como una prueba de la eficiencia del proyecto. Tres meses después, con base en documentos que contenían varias irregularidades y evidencia de corrupción en la administración del PCT, el Foro pidió una nueva investigación al panel, recibiendo una vez más una respuesta negativa.

Fue entonces que el liderazgo de la Contag decidió negociar con la IBRD y el gobierno federal en la creación de un nuevo programa de crédito de tierras, similar a los anteriores, pero con algunas modificaciones. Después de esto, la Contag continuó clasificando al Pст y al Banco de Tierras como

${ }^{20}$ El Foro fue creado en 1995 y en ese tiempo involucraba a más de 30 organizaciones, incluyendo al mst y Contag. 
MALR, pero diferenciándolos de «su» propio programa, considerándolo como una línea de crédito «complementario» a la reforma agraria. Por consiguiente, el préstamo del IBRD prometido al Banco de Tierras fue redirigido a un nuevo programa. La unión política del foro contra el MALR se rompió y después de varios conflictos internos se abandonó el tema.

Varias evaluaciones mostraron la incapacidad de MALR para estimular el desarrollo económico y la justicia social en el campo brasileño y en otras naciones, por lo que este modelo no sustituyó la reforma agraria redistributiva (véase Borras, 2003; Sauer, 2009; Pereira, 2007 y 2012). A pesar de avances técnicos que mejoraron los programas de este tipo - por ejemplo, incrementando mecanismos de participación y transparencia a través de mediación sindical - las medidas no fueron suficientes para superar los límites estructurales de este modelo, como la dependencia de la oferta de tierras en propietarios y la incapacidad de democratizar la estructura de tenencia de tierras y lograr esta escala social, debido al pago previo en dinero a precios de mercado.

En 2001-2002, la administración de Cardoso llevó a cabo dos acciones importantes. La primera fue registrar las solicitudes para acceso a tierras en las oficinas postales en todo el país. Con una propaganda intensa en los medios de comunicación, la campaña prometió «reforma agraria sin conflictos». El número de personas registradas llegó a 839,715, pero ninguna se asentó. La segunda acción consistió en la paralización por dos años de las inspecciones del INCRA de años ocupados, lo que minó la conclusión de los procesos de expropiación.

Mientras, como una categoría política, los «sin tierra» ganaron notoriedad durante los años noventa, la de «agricultura familiar» tuvo un mayor impacto. Algunos factores fueron decisivos en este surgimiento, incluyendo: a) el incremento en la diferenciación social del trabajo en agricultura; b) el declive del peso político de los asalariados rurales; c) disputas dentro de los movimientos sindicales campesinos, en particular entre Contag y DNTR-CUT; d) la evaluación de los efectos de la modernización de la agricultura y el neoliberalismo y la creciente convicción en la necesidad de un modelo alternativo para el desarrollo rural, 
más «democrático» e «inclusivo», aunque en el marco del capitalismo; e) reflexión dentro el movimiento sindical sobre el rol de la agricultura familiar en el desarrollo, tomando la experiencia europea como referencia principal (Favareto, 2006; Medeiros, 2001 y 2010).

La movilización liderada por la Contag y la DNTR-CUT y la convergencia progresiva entre ellas resultó en la afiliación de la Contag a la CUT en 1995 y la extinción de la DNTR. También resultó en la creación del Programa Nacional de Fortalecimiento de la Agricultura Familiar (Programa Nacional de Fortalecimento da Agricultura Familiar - Pronaf-) en 1996, consagrando la "agricultura familiar" ${ }^{21}$ como una categoría política. La diseminación de esta categoría reconfiguró los términos de debate sobre políticas públicas o relacionadas con la producción y comercialización, crédito, agroindustrialización, cooperativismo, al igual que la reforma agraria misma - que perdió su posición central para el movimiento sindical-. Sin embargo, las divergencias entre el sindicalismo de cut y Contag continuaron en una disputa permanente sobre quién era el portavoz de los «agricultores familiares» como un grupo, lo que también resultó en el surgimiento de otra organización, la Federación de Trabajadores Agrícolas Familiares (Federação dos Trabalhadores na Agricultura Familiar -Fetraf-) (Medeiros, 2010; Picolotto, 2011).

Por otro lado, la fuerza que este grupo adquirió en el campo de la política de identidad de la aprobación estatal, se sumó a su movimiento hacia el análisis del mundo rural, resultando en el abandono del concepto de campesinado en los años noventa. El mst y Vía Campesina estaban interesados en rescatar ese concepto como una identidad política y un

\footnotetext{
${ }^{21}$ Después, la ley 11.326/2006 definiría al agricultor familiar como al productor que no poseía un área superior a cuatro unidades fiscales y que usaba mayormente trabajo familiar en actividades en el establecimiento, obteniendo de esas actividades su fuente de ingreso principal y dirigiéndolas con su familia. Se debe enfatizar que el IBGE incorporó la definición de «agricultura familiar» de esta ley, lo que permitió por primera vez en el censo agrícola de 2006 (llevado a cabo cada 10 años) la identificación de su tamaño y distribución espacial. Sin embargo, categorías como «agronegocios»o «agricultura de empleador» no tenían definiciones oficiales. Por tanto, para el IBGE, los establecimientos agrícolas que no encajan en la definición de «agricultura familiar» simplemente son denominados como «agricultura no familiar».
} 
instrumento de análisis durante los años 2000, a veces de una forma complementaria, a veces compitiendo con el concepto de agricultura familiar, dependiendo del antagonista, lo que claramente denotó la existencia de una disputa por la representación de los segmentos del mundo de trabajo rural y la forma de clasificarlos ( $c f r$. Vía Campesina, 2002; MST, 2013).

\section{ADMINISTRACIONES DE LULA DA SILVA (2003-2010) Y DILMA ROUSSEFF (2011-2014)}

La victoria de Lula en las elecciones de 2002 fue un hecho histórico en la historia de Brasil. Después de tres derrotas, el candidato del $\mathbf{P T}$ finalmente logró la Presidencia, apoyado por una variada coalición política que incluyó fuerzas populares y conservadoras. «La esperanza derrotó al miedo», decía la frase de Lula, quien una vez electo señaló un cambio de ruta después de más de una década de neoliberalismo. Sin embargo, los compromisos de campaña, las promesas de que no habría «ruptura de contratos», la composición de los ministerios, el perfil del apoyo del gobierno en el Congreso, las primeras medidas adoptadas - como la reforma del seguro social que era socialmente regresivo en términos de derechos - y, sobre todo, la política económica implementada, pronto mostrarían que no habría una ruptura en la estructura del poder del país.

Sin embargo, el inicio del gobierno estuvo marcado por una enorme expectativa por parte de los campesinos y movimientos sociales por la realización de una reforma agraria efectiva. El número de ocupaciones y familias en campamentos organizados por el MST se disparó, regresando la cuestión al centro de la agenda política. Individuos apoyados por la organización fueron nominados al comité de la INCRA.

La reacción de los empleadores fue inmediata en forma de violencia contra campesinos activistas, que retornó a los niveles de los años ochenta (IPEA, 2011: 238). El Poder Judicial también fue llamado a la acción en los estados, emitiendo órdenes de arresto y notificaciones de desalojo, 
que alcanzaron niveles récord. Una campaña en los principales medios de comunicación criminalizó a los movimientos sociales, en particular al MST, y acusó fuertemente al gobierno federal de omisión o complicidad.

Mientras tanto, a pedido del gobierno, un equipo de investigadores coordinados por Plínio de Arruda Sampaio preparó una nueva propuesta para un Plan Nacional de Reforma Agraria (PNRA). Basada en estudios consistentes, la propuesta mostró la existencia de tierras disponibles para la reforma agraria en todos los estados de la Federación. Aún más, mostró la existencia de una demanda potencial estimada en seis millones de familias sin tierra o desde minifundios, una demanda de emergencia de alrededor de 180,000 familias en campamentos, y una demanda explícita de alrededor de un millón de familias, compuestas por el público registrado en la oficina postal en 2001 y en campamentos. La propuesta también estableció un objetivo de un millón de familias asentadas entre 2004-2007 y regresó a la idea de «áreas reformadas» con el propósito de sobrellevar la naturaleza ocasional de la política de asentamientos y promover sinergia entre las políticas públicas. Los cotos para financiar esto $-y$ los medios - también se detallaron, reforzando su factibilidad.

La propuesta fue enviada al gobierno en octubre de 2003 y contaba con el apoyo total de los movimientos campesinos. Sin embargo, el gobierno federal rechazó el documento, y en su lugar anunció el 20 PNRA, con objetivos mucho más bajos. Unos días antes el presidente del INCRA y su equipo habían sido despedidos, en el nombre de la gobernabilidad.

Entre otros objetivos, el $2^{\circ}$ PNRA estipulaba el asentamiento de 400,000 familias para 2006; las de regularización de la tenencia de tierras de 500,000 familias; la expansión de créditos de tierra a 130,000 familias a través del recientemente creado Programa Nacional de Crédito de Tierras (Programa Nacional de Crédito Fundiário - PNCF-), financiado por el IBRD; la provisión de asistencia técnica, entrenamiento, crédito y políticas de comercialización, para todos los asentados en áreas de la reforma agraria; la promoción de igualdad de género en los asentamientos; y dando a todos aquellos que viven en los remanentes 
de los quilombos título de sus tierras. ${ }^{22}$ También estaba prevista la actualización de los índices productivos agrícolas. ${ }^{23}$

Incluso con los objetivos más modestos, inferiores a los rechazados por el gobierno, el segundo PNRA se desempeñó peor de lo que se pretendía. Esto es lo que se puede comprender de las posiciones tomadas por las principales partes involucradas. En una carta enviada al presidente Lula en octubre de 2005, el MST criticó la política agraria vigente, denunciando el incumplimiento de los objetivos de asentamientos, el abandono de miles de familias en campamentos, y la no actualización de los índices de productividad. Al mismo tiempo, criticaron el apoyo político y financiero otorgado a los agronegocios.

En marzo de 2006, seis organizaciones evaluaron la política agraria de la administración de Lula (MST et al., 2006). ${ }^{24}$ De las 39 medidas evaluadas, 10 fueron consideradas positivas y 29 negativas. La mayoría de las medidas evaluadas como positivas fueron consideradas secundarias y parciales, mientras que las negativas eran estructurales.

El desempeño de la política agraria de la administración de Lula demostró en la práctica lo que indicaban los documentos oficiales: el debilitamiento de la reforma agraria como una política estructural y

22 Los quilombos eran áreas donde los fugitivos o esclavos liberados vivieron antes del fin de la esclavitud en 1888. La brecha abierta por la Constituyente de 1988 estimuló un movimiento que involucraba a más de 2,000 comunidades rurales negras, que ahora demandaban su reconocimiento como remanentes de los quilombos.

${ }_{23}$ Todas las propiedades rurales que eran más grandes que 15 módulos fiscales eran susceptibles a la expropiación con fines de reforma agraria, una vez que no hayan cumplido simultáneamente con los requerimientos de explotación económica racional, observar la legislación laboral y cumplir con la legislación ambiental. De hecho, sólo se tomaron en cuenta los requerimientos de explotación económica, ya que los índices de productividad fueron establecidos en 1975 y reflejaban los estándares en ejercicio en esa época, existieron menos áreas susceptibles a la expropiación en concordancia con los criterios económicos. La revisión de estos índices es una medida demandada por la legislación en ejercicio y por la cual el único responsable es el Ejecutivo, pero no se aplica. Todas las organizaciones de empleadores tomaron posiciones en contra de esta medida.

${ }^{24}$ Además del mst, fue firmado por el Movimiento de Pequeños Agricultores (Movimento de Pequenos Agricultores - MPA-), el Movimiento de Mujeres Campesinas (Movimento de Mulheres Camponesas - MMC-, el Movimiento de Personas Afectadas por las Represas (Movimento dos Atingidos por Barragens - МАВ-), СРТ У ABRA. 
su transformación en una medida de reducción de la pobreza rural y la presión social. Un análisis de la documentación elaborada por el gobierno y el PT hasta 2006 mostró que la concepción de reforma agraria existente fue debilitada desde un punto de vista conceptual y pragmático hasta convertirse en una acción residual y periférica de compensación social, al extremo de que: a) el establecimiento de objetivos anuales de asentamientos se detuvo; $b$ ) el concepto de áreas reformadas perdió importancia; c) la expropiación ya no se consideraba como el instrumento principal para obtener tierras; d) el crédito de tierras ganó importancia como un instrumento innovador; e) desapareció la mención de la actualización de los índices de productividad como una medida indispensable para expandir la tierra disponible para la reforma agraria (Carvalho, 2007). La promesa de una «reforma agraria extendida, masiva y de calidad, como una parte fundamental de un nuevo proyecto de desarrollo nacional», como dijo el manifiesto de Lula durante la campaña de reelección de 2006, no fue más que retórica electoral. En los años siguientes, este debilitamiento marcaría la agenda del segundo mandato de Lula, siendo consolidado durante la administración de Dilma Rousseff (véase ip EA, 2013: 336-374; MST, 2013a y 2014).

Por otro lado, el gobierno federal adoptó políticas públicas importantes para apoyar la producción y comercialización, lo que benefició a las familias agrícolas y a aquéllos asentados por la reforma agraria, como el Programa de Adquisición de Alimentos (Programa de Aquisição de Alimentos - PAA-), la Política Nacional de Asistencia Técnica y Expansión Rural (Política Nacional de Assistência Técnica e Extensão Rural - Pnater -) y la ley que dispuso 30 por ciento de los fondos de la Política Nacional de Alimentación Escolar (Política Nacional de Alimentação Escolar - PNAE-) para la compra de productos de familias agrícolas y de asentamientos. Estas políticas tuvieron un alcance limitado y sufrieron la ausencia de recursos para hacerse masivas, pero representaron mucho más de lo que habían hecho los gobiernos anteriores (IPEA, 2011 y 2012). 
El debilitamiento de la reforma agraria en la agenda política federal fue uno de los resultados del poder de los agronegocios en la economía y política brasileña. Su expansión durante los años 2000 fue propulsada por el incremento en los precios internacionales de productos agrícolas, y muy en especial por la demanda de China, el socio comercial más importante de Brasil. Más aún, los agronegocios se beneficiaron de la política económica, las recurrentes renegociaciones de la deuda de los grandes prestatarios, y la canalización de recursos públicos para apoyar estrategias de conglomeración e internacionalización de negocios. La acción estatal, a través de varios instrumentos y agencias, priorizó la promoción de los cultivos para exportación y la producción de alimentos para animales, agrocombustibles, papel y celulosa, fortaleciendo los agronegocios como una estructura de poder (Delgado, 2010).

Desde el inicio de los años 2000, las organizaciones comerciales buscaron expandir el volumen de tierra para la expansión de la producción de productos agrícolas y bloquear la reforma agraria, usando las siguientes medidas: a) redefinición de la Amazonia Legal, ${ }^{25}$ excluyendo los estados de Mato Grosso, Tocantins y Maranhão, por tanto, permitiendo la incorporación inmediata de 145 millones de hectáreas, debido a la reducción del área usada para preservación ambiental; $b$ ) reducción de 80 por ciento a 50 por ciento del área de la reserva legal de la Amazonia; c) provisión de crédito para aquellos que cometieron crímenes ambientales; d) privatización de tierras públicas hasta 1,500 hectáreas sin licitación pública en la región amazónica; e) reducción de la región fronteriza donde los extranjeros tienen prohibido comprar tierra de 150 a 50 kilómetros; f) revocación de la cláusula constitucional permitiendo a los vestigios de los quilombos titular sus tierras; $g$ ) eliminación de los índices de productividad que apoyaban la expropiación con fines de reforma agraria; $b$ ) la transferencia de responsabilidad del Ejecutivo al Legislativo para actualizar

${ }^{25}$ La Amazonia Legal es un área que corresponde a 50 por ciento del territorio brasileño y cubre ocho estados y parte del estado de Maranhão, con un total de cinco millones de kilómetros cuadrados. Viviendo ahí en 2005 estaba 56 por ciento de la población indígena del Brasil (alrededor de 250,000 personas y 80 etnicidades). 
índices de productividad y llevar a cabo expropiación con fines de reforma agraria; i) eliminación del grado de utilización de tierras ( grau de utilização da terra - GUT-), uno de los parámetros técnicos usados para medir la productividad de las propiedades rurales, de ese modo sólo se utilizaría el grado de eficiencia de explotación (grau de eficiência de exploração GEE-), algo que mide la eficiencia del área cultivada sin tomar en cuenta qué tanto del total de la propiedad representa; j) transferir la competencia de demarcar tierras indígenas del Ejecutivo al Congreso (peC, núm. 215) (Cfr. Almeida, 2010; IPEA, 2012 y 2013).

En relación con la política ambiental, la principal iniciativa consistió en hacer más flexible la legislación en vigencia, oponiendo a aquellos que defendían la regulación pública y la función socioambiental de la tierra y a aquellos que defendían el derecho absoluto de la propiedad y la mercantilización de la naturaleza. Los conflictos se concentraron en la aprobación del nuevo código forestal, que reemplazó al anterior, de 1965. El caucus ruralista (bancada ruralista) defendió: a) la amnistía de los propietarios rurales que no habían cumplido con la legislación ambiental; b) la reducción de las áreas que debían ser preservadas en cualquier propiedad rural (la llamada Reserva Legal); c) la expansión de la frontera agrícola a través de la apertura de áreas donde esto no podría suceder de forma legal. Después de una disputa intensa el resultado fue muy favorable para los intereses de los agronegocios (IPEA, 2013: 332-336; Sauer y França, 2012).

\section{CONCLUSIÓN}

A pesar de las ganancias en productividad en las ramas de producción intensivas en los últimos 50 años, el modelo agrícola brasileño se ha autosostenido y expandido a través de la apropiación extensiva de nuevas áreas. Es un modelo que depende de la oferta elástica de tierras, que requiere del mantenimiento de un inventario de tierras sin uso y sin explotación, careciendo de cualquier restricción en su uso. El proceso de modernización de la agricultura, en lugar de atenuar, empeoró este rasgo estructural. El resultado de esto 
fue el veto de la clase dominante a cualquier reforma agraria, la presión para hacer las leyes ambientales más flexibles, y el rechazo a cualquier mención de control social sobre el derecho a la propiedad. Igualmente, se dio lugar a la criminalización de los movimientos sociales por los medios y el Estado.

La concentración de posesión de tierras siguió jugando un papel fundamental en la producción y reproducción de justicia y la desigualdad de poder, ingresos y riqueza en el país. Lejos de la imagen de «eficiencia» que los intereses comerciales deseaban transmitir, el «éxito» de los agronegocios estaba basado en la explotación de los campesinos, devastación ambiental, el uso indiscriminado de agrotoxinas y violencia contra los campesinos, pueblos indígenas y quilombolas, bajo el auspicio directo e indirecto del Estado. Estos rasgos son constitutivos del modelo agrario dominante y no excepciones.

A pesar de la reinvención y activismo de los campesinos, sindicatos y movimientos populares, los agronegocios se han ratificado como la principal fuerza en la estructuración de las relaciones sociales en agricultura brasileña. Medio siglo después es evidente que la cuestión agraria que existe en Brasil no es la del capital, sino más bien la del mundo laboral. Contrario a lo que el portavoz de los agronegocios afirma, la reforma agraria no es un eslogan anacrónico en Brasil; al contrario, sigue siendo actual y asume un nuevo contenido y significado, estando cada vez más asociado por campesinos con alimentación más saludable (el país se ha convertido en campeón en el uso de agrotoxinas), preservación ambiental y soberanía alimentaria.

\section{BIBLIOGRAFÍA}

Alentejano, Paulo (2000), «O que há de novo no rural brasileiro?», Terra Livre, núm. 15.

Almeida, Alfredo (2010), «Agroestratégias e desterritorialização: direitos territoriais e étnicos na mira dos estrategistas dos agronegócios», en Alfredo Almeida et al. (eds.), Capitalismo globalizado e recursos territoriais, Río de Janeiro, Lamparina. 
Borras Jr., Saturnino (2003), «Questioning Market-Led Agrarian Reform: Experiences from Brazil, Colombia and South Africa», Journal of Agrarian Change, vol. 3, núm. 3 .

Bruno, Regina (1997), Senhores da terra, senhores da guerra, Río de Janeiro, Forense/Edur.

(2008), Um Brasil ambivalente: agronegócio, ruralismo e relações de poder, Río de Janeiro, Mauad/Edur.

Caldart, Roseli (2000), Pedagogia do Movimento Sem Terra, Petrópolis, Vozes.

Camargo, Aspásia (1981), «A questão agrária: crise de poder e reformas de base (1930-64)», en Bóris Fausto (ed.), História Geral da Civilização Brasileira. O Brasil Republicano, São Paulo, Difel, vol. 3, tomo III.

Carneiro, Ana y Marta Ciocari (2010), Retrato da repressão política no campo: Brasil (1962-1985), Brasilia, MDA.

Carter, Miguel (ed.) (2014), Challenging Social Inequality: The Landless Rural Workers Movement and Agrarian Reform in Brazil, Durham, Duke University Press.

Carvalho Filho, José Juliano (2001), «Política agrária do governo FHC: desenvolvimento rural e a Nova Reforma Agrária», en S. Leite (ed.), Políticas públicas e agricultura no Brasil, Porto Alegre, Edufrgs.

(2007), «O governo Lula e o esvaziamento da reforma agrária», Reforma Agrária, vol. 34, núm. 2.

Delgado, Guilherme (1985), Capital financeiro e agricultura no Brasil (19651985), São Paulo, Ed. Unicamp.

(2010), «A questão agrária e o agronegócio no Brasil», en M. Carter (ed.), Combatendo a desigualdade social: o mst e a reforma agrária no Brasil, São Paulo, UNESP.

Delgado, Nelson Gordiano (2009), Papel e lugar do rural no desenvolvimento nacional, Río de Janeiro, IICA/MDA.

D'Incao, Maria Conceição (1990), «O governo de transição: entre o velho e o novo projeto político agrícola de reforma agraria», Lua Nova, núm. 20.

Dreifuss, René (1984), 1964: a conquista do Estado. Ação política, poder e golpe de classe, Petrópolis, Vozes.

(1989), O jogo da direita na Nova República, Petrópolis, Vozes.

FACHIN, Luiz Edson (1985), «O Direito e o avesso na reforma agrária da Nova República», Reforma Agrária, num. 3.

(1993), «Depois da Lei Agrária: o que muda no campo brasileiro?» Democracia na Terra, núm. 10. 
Favareto, Arilson (2006), «Agricultores, trabalhadores: os trinta anos do novo sindicalismo rural no Brasil», Revista Brasileira de Ciências Sociais, vol. 21, núm. 62.

Fernandes, Bernardo (2000), A formação do mst no Brasil, Petrópolis, Vozes.

Fernandes, Florestan (1985), Nova República?, Río de Janeiro, Zahar.

Ferrante, Vera Lucia (19949, «Os herdeiros da modernização: grilhões e lutas dos bóias-frias», São Paulo em Perspectiva, vol. 8, núm. 3.

Ferreira, Brancolina et al. (2009), "Constituição vinte anos: caminhos e descaminhos da reforma agrária - embates (permanentes), avanços (poucos) e derrotas (muitas)», Acompanbamento e Análise de Politicas Sociais (IPEA), vol. 2, núm. 17.

Gomes da Silva, José (1987), Caindo por terra: crises da reforma agrária na Nova República, São Paulo, Busca Vida.

(1989), Buraco negro: a reforma agrária na Constituinte, São Paulo, Paz e Terra.

(1996), A reforma agrária na virada do milênio, Campinas, ABRA.

Gonçalves Neto, Wenseslau (1997), Estado e agricultura no Brasil, São Paulo, Hucitec.

Graziano da Silva, José (1982), A modernização dolorosa, Río de Janeiro, Zahar. (1985), Para entender o Plano Nacional de Reforma Agrária, São Paulo, Brasiliense.

Ianni, Octavio (1979), Colonização e contra-reforma agrária na Amazônia, Petrópolis, Vozes.

(1979a), Ditadura e agricultura, Río de Janeiro, Civilização Brasileira. (1984), Origens agrárias do Estado Brasileiro, São Paulo, Brasiliense.

IBRD (1997), Project Appraisal Document to Brazil for Land Reform and Poverty Alleviation Pilot Project, Washington, Report núm. 16342-BR.

IPea (2010), «Desenvolvimento rural», Acompanbamento e Análise de Políticas Sociais, núm. 18.

(2011), «Desenvolvimento rural», Acompanbamento e Análise de Políticas Sociais, núm. 19.

(2012), «Desenvolvimento rural», Acompanhamento e Análise de Políticas Sociais, núm. 20.

(2013), «Desenvolvimento rural», Acompanbamento e Análise de Políticas Sociais, núm. 21.

Leite, Sergio (2001), «Padrão de financiamento, setor público e agricultura no Brasil», en S. Leite (ed.), Políticas públicas e agricultura no Brasil, Porto Alegre, Ufrgs. 
Leite, Sergio y Rodrigo Ávila (2007), Um futuro para o campo, Río de Janeiro, Vieira \& Lent.

Martins, Jose de Sousa (1981), Os camponeses e a politica no Brasil, Petrópolis, Vozes.

(1984), A militarização da questão agrária no Brasil, Petrópolis, Vozes.

Medeiros, Leonilde Servolo (1983), A questão da reforma agrária no Brasil (19551964), Master's Thesis, São Paulo, USP.

(1989), História dos movimentos sociais no campo, Río de Janeiro, FASE.

(2001), «Sem terra, assentados, agricultores familiares: considerações sobre os conflitos sociais e as formas de organização dos trabalhadores rurais brasileiros», en N. Giarraca (ed.), ¿Una nueva ruralidad en América Latina?, Buenos Aires, Clacso.

(2002), Movimentos sociais, disputas politicas e reforma agrária de mercado no Brasil, Río de Janeiro, CPDA/UfRRJ Y UNRISD.

(2010), «Agricultura familiar no Brasil: aspectos da formação de uma categoria política», en M. Manzanal y G. Neiman (eds.), Las agriculturas familiares del Mercosur: trayectorias, amenazas y desafios, Buenos Aires, Ciccus.

MendonçA, Sonia (2011), O patronato rural no Brasil recente, Río de Janeiro, ufrJ. Mepf (1997), Diretrizes do processo de descentralização da reforma agrária, Brasília. (1998), Mudanças legais que melhoraram e apressaram as ações da reforma agrária, Brasília.

(1999), Agricultura familiar, reforma agrária e desenvolvimento local para um novo mundo rural, Brasília.

(1999a), A nova reforma agrária, Brasília.

MST (2013), Programa agrário do MST - Texto em construção para o VI Congresso Nacional, São Paulo, abril.

(2013a), Carta da Direção Nacional do Mst à Presidenta Dilma Rousseff, Arapongas, 4 de febrero.

(2014), Carta à Presidenta Dilma Rousseff, Brasília, 14 de febrero.

MST et al. (2006), Balanço das medidas do governo Lula (2002-2006) em relação à agricultura camponesa e reforma agrária no Brasil, São Paulo.

Palmeira, Moacir (1985), «A diversidade da luta no campo: luta camponesa e diferenciação do campesinato», en V. Paiva (ed.), Igreja e questão agrária, São Paulo, Loyola.

(1994), «Burocracia, política e reforma agrária», en L. Medeiros et al. (eds.), Assentamentos rurais: uma visão multidisciplinar, São Paulo, UNESP.

Palmeira, Moacir y Sergio Leite (1997), Debates econômicos, processos sociais e lutas políticas: reflexões sobre a questão agrária, Río de Janeiro, Debates CPDA, núm. 1 . 
Pereira, João Márcio Mendes (2007), «The World Bank's'Market-Assisted Land Reform' as Political Issue: Evidence from Brazil (1997-2006)», European Review of Latin American and Caribbean Studies, núm. 82.

(2012), «Evaluation of the Cédula da Terra Project (1997-2002)», Estudos Avançados, vol. 26, núm. 75.

Picolotto, Everton (2011), As mãos que alimentam a nação: agricultura familiar, sindicalismo e política, $\mathrm{PhD}$ 'Thesis, Río de Janeiro, UfRRJ-CPDA.

Ricci, Rudá (1999), Terra de ninguém: sindicalismo rural e crise de representação, Campinas, Unicamp.

Sauer, Sérgio (2009), «Market-Led Agrarian Reform in Brazil: the Costs of an Illusory Future», Progress in Development Studies, vol. 9, núm. 2.

SAuer, Sérgio y Franciney França (2012), «Código Florestal, Função Socioambiental da Terra e Soberania Alimentar», Caderno CRH 25, núm. 65.

Stédile, João Pedro y Bernardo Mançano Fernandes (1999), Brava gente: a trajetória do mst e a luta pela terra no Brasil, São Paulo, Editora Fundação Perseu Abramo.

TAPIA, Jorge (1986), Capitalismo e questão agrária: um estudo sobre as alternativas para a reforma agrária no Brasil (1946-64), Master's Thesis, Campinas, Unicamp. Van Zyl, J. y H. Binswanger (1996), «Market Assisted Rural Land Reform: How will it Work?», en J. Van Zyl, J. Kirsten y H. Binswanger (eds.), Agricultural Land Reform in South Africa: Policies, Markets and Mechanisms, Nueva York, Oxford University Press.

Veiga, José Eli da (1990), A reforma agrária que virou suco, Petrópolis, Vozes.

Via Campesina (2002), Histórico, natureza, linhas políticas internacionais e projeto para a agricultura brasileira, São Paulo, Via Campesina-Brasil.

Welch, Cliff (1999), The Seed Was Planted: The São Paulo Roots of Brazil's Rural Labor Movement, 1924-1964, Pennsylvania, Penn State Press. 